\title{
Adolescent Social Anxiety and Substance Use: The Role of Susceptibility to Peer Pressure
}

\author{
Anke W. Blöte, Anne C. Miers, and P. Michiel Westenberg \\ Institute of Psychology, Unit of Developmental and Educational Psychology, Leiden University, Leiden, Netherlands \\ Correspondence should be addressed to Anke W. Blöte; bloete@fsw.leidenuniv.nl
}

Received 29 April 2016; Accepted 24 August 2016

Academic Editor: Elena Nicoladis

Copyright ( 2016 Anke W. Blöte et al. This is an open access article distributed under the Creative Commons Attribution License, which permits unrestricted use, distribution, and reproduction in any medium, provided the original work is properly cited.

\begin{abstract}
The aim of this study was to further our understanding of the link between social anxiety and substance use in adolescents, in particular the role susceptibility to peer pressure plays in this link. The relation between social anxiety and susceptibility to peer pressure was studied in two community samples ( $n=534$ and $n=117)$ each consisting of two age groups (12-13 and $15-17$ years). The relation of these two variables with substance use was evaluated in the second sample using regression analysis. Social anxiety was related to susceptibility to peer pressure in both groups and not related to substance use in the younger group and negatively related to substance use in the older group. Susceptibility to peer pressure acted as a suppressor in the relation between social anxiety and substance use. Results suggest that socially anxious adolescents basically avoid substance use but, if susceptible, may yield to peer pressure and start using substances. Parents, teachers, and therapists should be aware of this susceptibility to possibly negative peer pressure of socially anxious adolescents.
\end{abstract}

\section{Introduction}

Previous studies on the relation between social anxiety and substance use in young individuals have yielded ambiguous results with some studies finding a positive relation $[1,2]$ and others finding no relation or a negative one $[3,4]$. The current study aimed to further our insight into the link between social anxiety and substance use in adolescents by evaluating the potential role susceptibility to peer pressure plays in adolescents' substance use.

Social anxiety disorder (SAD, or social phobia) is described in the DSM-5 as a "Marked fear or anxiety about one or more social situations in which the individual is exposed to possible scrutiny by others" [5]. However, not all socially anxious individuals meet the criteria for SAD. Social anxiety is seen as a continuous variable with some individuals having low or average social anxiety levels and others having high to very high levels [6]. Only those who experience life interference because of distress in and avoidance of social situations are diagnosed with SAD. As far as youth is concerned, social fears are part of the normal development of children and adolescents [7]. Some of these young individuals are exceptionally anxious and develop high levels of social anxiety or even a social anxiety disorder, most likely in their adolescent years [6]. A US study found that $8.6 \%$ of adolescents met lifetime criteria for SAD [8]. The number of adolescents with subclinical levels of social anxiety is much larger with percentages varying between 27 and $47 \%[9,10]$.

Generally, drinking, smoking, and drug use start in adolescence [11-13]. An early start of this substance use predicts later dependence and abuse. For example, youth who start drinking or smoking in early or midadolescence have a higher risk for alcohol use disorder [14] or daily smoking $[15,16]$ later in life than those who start at a later age. Because substance use frequently starts in adolescence and has consequences for later use or even abuse, it seems very important to learn more about factors that facilitate or impede the beginning of these behaviors in this period of life. One of the factors that may be related to substance use is social anxiety.

Individuals with $\mathrm{SAD}$ have higher rates of smoking, drinking, and drug use than non-socially anxious individuals [e.g., [1]]. This is also true for individuals with subclinical levels of social anxiety $[2,17]$. In a large epidemiological study 
among adolescents and adults (15-54 years old), Kessler et al. [18] found that more than $40 \%$ of the respondents with social phobia also had substance use disorder. In a younger sample of 14-24-year-olds, again more than $40 \%$ of those with social phobia had such a disorder: $31.9 \%$ for nicotine, $19.4 \%$ for alcohol, and $7.5 \%$ for drug use [10]. A prospective study of boys starting in first grade and continuing through high school showed that boys with higher levels of social anxiety started earlier with drinking and smoking (but not with using marijuana) [19]. Another prospective study starting with senior high school students found that SAD was a predictor of later alcohol and cannabis dependence [20].

However, not all studies have found that substance use of young people is associated with social anxiety disorder or social anxiety related symptoms. For example, in children aged 9 to 12 years, a negative relationship was found between internalizing behavior and initiation of alcohol use [21] and one review concluded that in community samples substance dependency was not related to anxiety disorders in adolescents [22]. Furthermore, studies on undergraduates' alcohol use reported no relation between social anxiety and alcohol use and problems or found a negative relation $[3,4]$. Possibly, socially anxious students avoid social situations like parties where people drink alcohol or abstain from drinking in these situations because they think that the alcohol may lower their self-control and they do not wish to embarrass themselves [23]. This avoidance of alcohol use would be in line with the self-presentation model developed for shyness [24]. According to this model, socially anxious individuals would fear that their behavior when drinking alcohol or using drugs might result in negative evaluations by others. They therefore would abstain from using it.

The present study aimed to increase our understanding of the association between social anxiety and substance use at an early stage of life when drinking, smoking, and drug use are initiated. In a person's lifetime, social anxiety appears to precede substance use [see review [25]]. In addition, social fears and social anxiety disorder predict later alcohol abuse [25] and nicotine dependency [16]. However, a question that has not yet been answered is why some socially anxious adolescents start smoking, drinking, or using drugs while others do not. Some studies suggest that peer pressure plays an important role in the initiation of drinking, smoking, and drug use and problems $[15,26]$ and that adolescents' substance use is related to their friends' substance use [17]. Peer pressure may be an important influence on initial use because "Those who drink, smoke, and use drugs typically enjoy an elevated status among their peers" [12, p. 1153]. There is a link between being liked by peers and substance use [27]. As far as socially anxious youth is concerned, peer pressure has been found to moderate the link between social anxiety disorder and problematic cannabis use [26]. Apart from the presence of a peer group exerting pressure to drink, smoke, or use drugs, the degree of susceptibility to this peer pressure is probably also important.

Being part of a peer group is seen by adolescents as a way to receive support and build friendships [28]. At this stage of development, susceptibility to peer pressure is particularly high. It is seen as a phase between individuation from parents and reaching a sense of identity [29]. Susceptibility to peer pressure gradually decreases during adolescence and is lower in boys than in girls $[30,31]$. Studies on individual differences in susceptibility to peer pressure are few [32]. One study suggested that susceptibility to peer pressure is linked to genetic factors [33]. Another study found that susceptibility to peer pressure, in particular the skill to handle deviant peer behavior, is one of the predictors of later substance use in adolescents [34].

Whether susceptibility to peer pressure is related to social anxiety has, to the best of our knowledge, not yet been studied. However, there are good reasons why such relation is to be expected. The fear of isolation and the fear of ridicule may play a role in this relation [35]. It may be easier for adolescents to resist peer pressure when they are relatively confident about their own social status $[17,36]$. Adolescents who feel that they are not doing well socially or are socially anxious may be inclined to follow peers, not feeling strong enough, socially, to choose their own route. Consequently, they may join others in substance use hoping to improve their social status and be part of the peer group.

In sum, the present study focused on the role of susceptibility to peer pressure in the link between social anxiety and early substance use (tobacco, alcohol, and cannabis). Three research questions were posed. (1) Is social anxiety in adolescents associated with elevated levels of susceptibility to peer pressure? (2) Is social anxiety in adolescents related to substance use? As stated above, results on the relation between social anxiety and substance use have been equivocal, especially in regard to young individuals. (3) Does susceptibility to peer pressure play a role in the initial stages of substance use in socially anxious adolescents? We did not know which role that would be. Susceptibility to peer pressure may be either a mediator or a suppressor variable [37]. This depends on whether there is a direct association between social anxiety and substance use. If social anxiety, susceptibility to peer pressure, and substance use are all positively related, susceptibility to peer pressure may be a mediator in the social anxiety substance use relation explaining why socially anxious adolescents use one or more substances. If social anxiety and substance use are not directly related or if social anxiety and susceptibility to peer pressure have opposite effects on substance use, susceptibility to peer pressure may turn out to be a suppressor variable [3, 37, 38]. Through high susceptibility to peer pressure, socially anxious adolescents would be drawn to give in to peer pressure and start to drink, smoke, or use drugs, whereas their social anxiety, including their fear of behaving in an inappropriate manner, would cause them to refrain from such behavior.

In the current study, two samples were included and each sample comprised a group of younger adolescents and a group of older adolescents. A group of younger adolescents was selected because it was expected that although most of them would not yet be users of tobacco, alcohol, and soft drugs (in The Netherlands, the term soft drugs is used for the different types of cannabis), few of them would already use one or more substances regularly; see for age-related prevalence in The Netherlands the National Drug Monitor [39]. This group would therefore present information about 
the early beginnings of substance use. A group of older adolescents was included in the study of whom we expected that a substantial proportion would use substances on a regular basis [39]. The first research question regarding the relation between social anxiety and susceptibility to peer pressure was investigated in one sample and then replicated in the second sample. Replication is important because previous studies on the relationship between social anxiety and susceptibility to peer pressure are lacking. For the second and third research questions involving social anxiety, susceptibility to peer pressure, and substance use, the second sample was used. Furthermore, a two-year follow-up measurement of substance use was used in order to investigate whether the role of susceptibility to peer pressure in the initial phase of substance use extends to future substance use as well.

\section{Methods}

2.1. Participants and Procedure. All participants were high school students from mainly White, middle class families in The Netherlands. Sample 1 consisted of 544 adolescents, students from five high schools. The sample comprised adolescents from two age groups: a younger adolescent group consisting of 12- and 13-year-olds ( $n=302,151$ boys) and an older adolescent group consisting of 15- to 17-year-olds $\left(n=242,129\right.$ boys). $\mathrm{M}_{\text {age }}$ of the younger group was 12.50 years, $S D=0.50$, and $\mathrm{M}_{\text {age }}$ of the older group was 15.65 years, $\mathrm{SD}=0.68$. The participants of Sample 1 were tested in their school classroom in the presence of a teacher and two experimenters (undergraduate students). The experimenters used a standard instruction that was also written out on the front page of the test booklet, to introduce the procedure. The participants completed four questionnaires including the SAS-A [40] and the RPI [30, 31]. The other two questionnaires are not relevant to the present study. Once they finished, participants were thanked for their participation and were given some sweets.

Sample 2 consisted of a selection of participants from the SAND study [41, 42]. The SAND study included four waves and assessed substance use at Waves 1 and 3 (T1 and T2 in the current study) with a period of two years in between. The retention rate from Wave 1 to Wave 3 was $75 \%$. From the first wave (T1), two groups of participants attending high school were selected $(n=117$; total high school sample $n=204)$ who were in the same age range as the participants of Sample 1 and who participated both at $\mathrm{T} 1$ and $\mathrm{T} 2$. The younger age group consisted of 49 adolescents (27 boys) and the older age group of 68 adolescents ( 32 boys). $\mathrm{M}_{\text {age }}$ of the younger group at $\mathrm{T} 1$ was 12.67 years, $\mathrm{SD}=0.43$, and $\mathrm{M}_{\text {age }}$ of the older group was 15.54 years, $\mathrm{SD}=0.61$. The participants came to the laboratory of the university individually and completed a number of questionnaires, among them were the SAS-A [40] and RPI $[30,31]$ on a PC. One week later, they came again to give an oral presentation [see [41]]. The health behavior questions used in the present study were part of a structured interview that took place after the oral presentation. The participants were interviewed by a trained Ph.D. student or research assistant. Participants in the SAND study received a monetary award.
The study using Sample 1 was approved by the Ethical Committee of the Psychology Department of the university and the SAND study (Sample 2) by the Medical Ethical Committee of the university. In both samples, adolescents actively assented to participate. The parents of participants in Sample 1 passively consented and the parents of participants in Sample 2 actively consented to their children's participation in the study.

\subsection{Instruments}

2.2.1. Social Anxiety Scale for Adolescents (SAS-A) [40]. The Dutch translation (H. Koot and E. Utens, unpublished) of the SAS-A was used to measure participants' trait social anxiety. The SAS-A consists of 18 items containing self-descriptive statements about social anxiety symptoms (e.g., I worry about what others think of me) and four filler items. Items are scored on a Likert scale ranging from 1 (not at all) to 5 (always). The internal consistency of the Dutch version is good [43]. In Sample 1, Cronbach's $\alpha$ was .90. In the total sample of the SAND study, Cronbach's $\alpha$ at T1 was .94.

\subsubsection{Resistance to Peer Influence (RPI) [31]. The Dutch} translation of this questionnaire [30] was used to measure susceptibility to peer pressure. The scale consists of 10 items describing more or less neutral peer influence situations, for example, "Some kids go along with their friends just to keep their friends happy" and "Some kids think it's better to be an individual even if people will be angry at you for going against the crowd." The items are presented in a format developed by Harter [44]. Each item presents the participant with two options which are both acceptable choices, that is, "some kids..., but other kids..." Participants indicate to which group they belong and to what degree they belong to this group. This results in a four-point scale. The RPI is suitable for use with a wide age range, from late childhood through young adulthood. Items from the original Dutch version were reverse scored so that scores reflect susceptibility to peer pressure rather than resistance to peer influence. The internal consistency of the Dutch version of the RPI is adequate with Cronbach's $\alpha \geq .70$ for different age groups [30]. In Sample 1 of the present study, Cronbach's $\alpha=.70$ and in the total sample of the SAND study $\alpha=.73$.

2.2.3. Health Questionnaire (HQ). To measure substance use, we selected three questions from the HQ developed for the SAND study: "Do you smoke regularly?", "Do you drink alcohol regularly?", and "Do you use soft drugs regularly?" Answer categories are yes and no. A substance use score was composed of counting the number of substances (cigarettes, alcohol, and cannabis) used resulting in a score ranging from 0 to 3 .

2.3. Data Analysis. To answer research questions 1 and 2 , correlational analyses were performed using the IBM SPSS 19 package. Research question 3 about the role of susceptibility to peer pressure in the relation between social 
TABLE 1: Ms (SDs) of the main study variables per sample and age group.

\begin{tabular}{|c|c|c|c|c|c|c|}
\hline & \multicolumn{2}{|c|}{ Sample 1} & \multicolumn{4}{|c|}{ Sample 2} \\
\hline & Younger group $(n=302)$ & Older group $(n=242)$ & $t$ & Younger group $(n=49)$ & Older group $(n=68)$ & $t$ \\
\hline Social anxiety & $1.99(0.57)$ & $2.06(0.62)$ & -1.41 & $2.29(0.70)$ & $2.28(0.79)$ & 0.70 \\
\hline $\begin{array}{l}\text { Susceptibility to peer } \\
\text { influence }\end{array}$ & $2.01(0.47)$ & $1.98(0.50)$ & 0.75 & $2.14(0.40)$ & $2.00(0.51)$ & 1.63 \\
\hline Substance use T1 & - & - & - & $0.14(0.46)$ & $1.01(0.94)$ & $-6.01^{* *}$ \\
\hline Substance use T2 & - & - & - & $0.37(0.57)$ & $1.26(0.75)$ & $-7.08^{* *}$ \\
\hline
\end{tabular}

${ }^{* *} p<.01$.

TABLE 2: Frequencies (percentages) of adolescents' substance use per age group and time point (Sample 2).

\begin{tabular}{|c|c|c|c|c|c|c|}
\hline & \multicolumn{3}{|c|}{$\mathrm{T} 1$} & \multicolumn{3}{|c|}{$\mathrm{T} 2$} \\
\hline & Cigarette smoking & Alcohol use & Cannabis use & Cigarette smoking & Alcohol use & Cannabis use \\
\hline Younger group $(n=49)$ & $2(4 \%)$ & $5(10 \%)$ & 0 & $3(6 \%)$ & $14(29 \%)$ & $1(2 \%)$ \\
\hline Older group $(n=68)$ & $20(30 \%)$ & $42(62 \%)$ & $7(10 \%)$ & $22(32 \%)$ & $58(85 \%)$ & $6(9 \%)$ \\
\hline
\end{tabular}

anxiety and substance use was examined with the PROCESS macro [45] retrieved from http://www.processmacro.org/. Bootstrap procedures used 1000 bootstrap samples and confidence intervals of $95 \%$.

We used PROCESS to perform a number of linear regression analyses to test indirect and direct paths from the independent variable (social anxiety) to the dependent variable (substance use). We tested two indirect paths: (a) a path from social anxiety at T1, via susceptibility to peer pressure and substance use both at $\mathrm{T} 1$, to substance use at T2 and (b) a path not involving susceptibility to peer pressure, going directly from social anxiety to substance use at T1 and then to substance use at T2. We also present the direct path from social anxiety at $\mathrm{T} 1$ to substance use at $\mathrm{T} 2$, although we were not primarily interested in predicting the increase of substance use over time. The focus of our interest was on understanding initial substance use that is persistent over time.

Gender and age (within the age groups) were added as covariates in the analyses. We controlled for age because previous studies found age effects for susceptibility to peer pressure $[30,31]$ and for substance use $[39,46]$. We controlled for gender because gender plays a role in the occurrence of social anxiety $[6,40]$, susceptibility to peer pressure $[30,31]$, and substance use [47].

\section{Results}

3.1. Preliminary Analyses. Ms and SDs of the main study variables are presented in Table 1 . Social anxiety and susceptibility to peer pressure did not differ significantly between the age groups, whereas substance use was significantly higher in the older than younger age group, both at T1 and T2. Table 2 shows that at T1 the younger age group did not use cannabis and $10 \%$ or less of them drank alcohol or smoked cigarettes. Adolescents in the older group at $\mathrm{T} 1$ reported smoking and drinking as well as cannabis use. More than $60 \%$ drank alcohol, nearly one-third smoked cigarettes, and $10 \%$ used cannabis. At T2, in both age groups, alcohol use had increased. In the younger age group, nearly 30\% drank alcohol and in the older age group more than $80 \%$.

3.2. Correlations between Main Study Variables. Answering research question 1, we found that in Sample 1 susceptibility to peer pressure correlated significantly and positively with social anxiety, $r=.25$ and $r=.29$, in the younger and older groups, respectively. This result was replicated in Sample 2, $r=.35$ and $r=.34$, in the younger and older groups, respectively (all $r$ 's are significant at a $p<.01$ level).

Substance use at T2 was significantly correlated with substance use at $\mathrm{T} 1$ in both age groups, with $r=.36, p<.01$, in the younger group and $r=.66, p<.01$, in the older group. In relation to research question 2, substance use did not significantly correlate with social anxiety in the younger age group (see Table 3 ). In the older age group, substance use at T1 was significantly correlated with social anxiety. This correlation was negative indicating that adolescents with higher levels of social anxiety reported less substance use.

In the older age group, substance use at T1 and at T2 was significantly and positively related to susceptibility to peer pressure. Although the corresponding correlations in the younger age group were only slightly lower than those in the older age group, they were not significant (it should be noted that the younger age group had a smaller $n$ which may explain why the correlations in this group did not reach significance).

Because social anxiety and susceptibility to peer pressure showed opposing effects on substance use (social anxiety had a negative effect or no effect on substance use depending on the age group, whereas susceptibility to peer pressure had a positive effect on substance use), susceptibility to peer pressure could not be a mediator but might be a suppressor of the effect of social anxiety on substance use $[$ see $[3,37,38]]$.

3.3. Path Analysis. The paths in the model for the younger age group are pictured in Figure 1. The path from social anxiety through susceptibility to peer pressure and substance use at $\mathrm{T} 1$ to substance use at $\mathrm{T} 2$ was nearly significant: effect $=$ .02 , LLCI $=-.0006$, and ULCI $=.13$ (for significance, the 
TABLE 3: Correlations of substance use at $\mathrm{T} 1$ and $\mathrm{T} 2$ with social anxiety and susceptibility to peer pressure at $\mathrm{T} 1$ per age group.

\begin{tabular}{lcccc}
\hline & \multicolumn{2}{c}{ Younger group $(n=49)$} & \multicolumn{2}{c}{ Older group $(n=68)$} \\
& Substance use T1 & Substance use T2 & Substance use T1 & Substance use T2 \\
\hline Social anxiety T1 & .03 & .00 & $-.26^{*}$ & -.08 \\
Susceptibility to peer pressure T1 & .19 & .21 & $.26^{*}$ & $.25^{*}$ \\
\hline
\end{tabular}

${ }^{*} p<.05$.

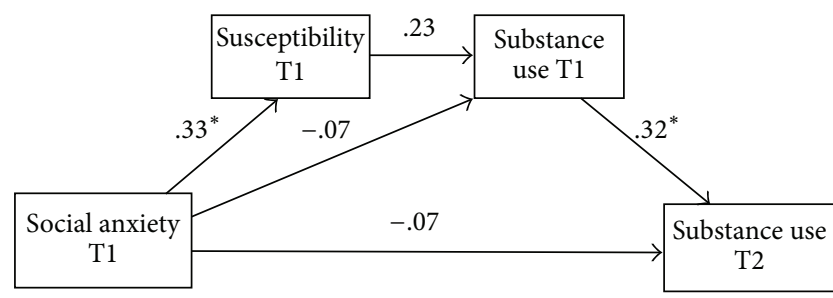

FIGURE 1: Standardized path estimates of the suppression model for the younger age group $(n=49) .{ }^{*} p<.05$.

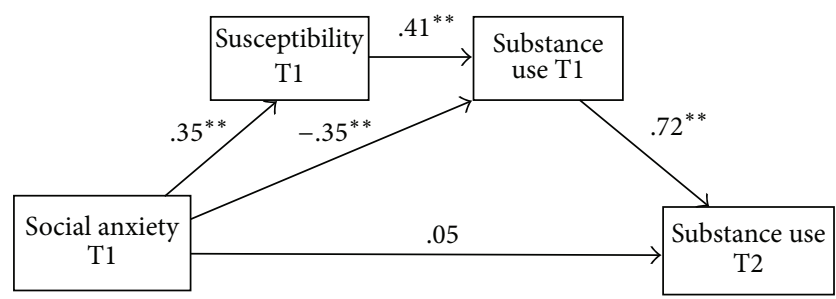

FIGURE 2: Standardized path estimates of the suppression model for the older age group $(n=68) .{ }^{* *} p<.01$.

confidence interval should not include zero). The path from social anxiety through substance use at $\mathrm{T} 1$ that excluded susceptibility to peer influence was not significant: effect $=$ -.02 , LLCI $=-.023$, and LLCI $=.07$. The direct path in this model, from social anxiety at $\mathrm{T} 1$ to substance use at $\mathrm{T} 2$, was not significant either (effect $=-.07, \mathrm{LLCI}=-.37$, and ULCI $=$ $.23)$.

In the older group, the path from social anxiety to susceptibility and substance use at $\mathrm{T} 1$ to substance use at T2 (see Figure 2) was significant: effect $=.10$, LLCI $=.04$, and ULCI $=.20$. Social anxiety at T1 was positively related to susceptibility to peer pressure at $\mathrm{Tl}$, susceptibility to peer pressure at $\mathrm{T} 1$ was positively related to substance use at $\mathrm{Tl}$, and substance use at $\mathrm{T} 1$ was positively related to substance use at T2. The alternate path that excluded susceptibility to peer pressure was also significant (effect $=-.25$, LLCI $=-.46$, and $\mathrm{ULCI}=-.09)$. In this path, social anxiety at $\mathrm{T} 1$ was negatively related to substance use at $\mathrm{T} 1$ which in turn was positively related to substance use at $\mathrm{T} 2$. The direct path in this model from social anxiety at $\mathrm{T} 1$ to substance use at $\mathrm{T} 2$ was not significant: effect $=-.05, \mathrm{LLCI}=-.16$, and ULCI $=.27$.

\section{Discussion}

Seemingly conflicting results about the substance use of socially anxious individuals have been reported in the literature. On the one hand, some studies repeatedly found that individuals with social anxiety have higher substance dependency and substance-related problems [10, 18, 25, 48]; on the other hand, some studies did not find a relation or found a negative relation between social anxiety and substance use $[3,4,21]$. The present study aimed to increase our understanding of the link between social anxiety and substance use by focusing on the early beginnings of substance use in adolescence and the role of susceptibility to peer influence in this relationship.

In line with the results of some studies using children and young adults $[3,4,21,49]$, the present study found a negative association between social anxiety and substance use in older adolescents suggesting that socially anxious youth avoid the use of substances. Interestingly, susceptibility to peer pressure acted as a suppressor variable in the relationship between social anxiety and substance use as indicated by the finding that the negative relation between social anxiety and substance use became stronger when susceptibility to peer pressure was taken into account.

The fact that susceptibility to peer pressure acts as a suppressor variable in the link between social anxiety and substance use may explain why socially anxious adolescents who are inclined to avoid using substances nevertheless start smoking, drinking, or using cannabis. We found that adolescents with higher levels of social anxiety are more susceptible to peer pressure and that susceptibility to peer pressure predicts substance use. Thus, social anxiety and substance use are indirectly positively related through susceptibility to peer pressure. The predicted substance use is not only concurrently linked with susceptibility to peer pressure but extends as a stable behavioral pattern over a longer period.

In sum, opposite effects appear to be at work in socially anxious adolescents. On the one hand, for different reasons, these adolescents may wish to avoid substance use. They may fear behaving in a way that is not approved of by most parents and teachers; or they may fear the direct consequences of substance use by losing control and embarrassing themselves as proposed by the self-presentation model [24]. On the other hand, socially anxious adolescents are susceptible to peer pressure and when peer pressure is high they possibly cannot resist and join their peers in smoking, drinking alcohol, or using cannabis [4]. This may have far-reaching consequences for their future lives, because once they have started using substances, there is a high chance that they will continue to use them. 
The present study found a high stability of substance use over a period of two years in the older adolescents. There may be at least two reasons for this. First, peer pressure may continue to influence their subsequent substance use and, second, substance use may help them feel better in social situations by easing their feelings of distress as proposed by the tension-reduction/self-medication models [50-52]. In this way, substance use becomes a coping mechanism in difficult situations $[3,53]$ with the risk of an increased use over time and possibly substance dependence and substancerelated problems later in their lives. It may well be that we see this effect in comorbidity studies of social anxiety disorder with substance use disorder in adults.

The positive relation between social anxiety and susceptibility to peer pressure was replicated in the two samples and the two age groups of the study presenting evidence of the reliability of this finding. As far as we are aware, the present study is the first one showing that socially anxious adolescents report a greater extent of peer influence on their behavior than less socially anxious adolescents. This influence is not a negative one per se. The instrument used for measuring susceptibility to peer pressure in this study, the RPI, is not specifically asking about peer pressure to take part in negative or antisocial behavior. On the contrary, most items ask about behavior in rather general situations [31]. Evidently, peer influence may be positive, neutral, or negative. In its positive form, it may foster prosocial behavior or participation in social gatherings. In its negative form, it may lead to antisocial and risk-taking behaviors, among them substance use. It all depends on the peer group concerned, their behavior, and ethical norms $[12,17,36]$.

The present study measured substance use in two groups of younger and older adolescents. Our conclusions are based on the results of the older group because in this group the tested relations reached statistical significance, while the effects in the younger group did not. The most important difference between the age groups concerns the direct relation between social anxiety and substance use. In the older group, these two variables are negatively related, whereas in the younger group they are not related. There may be two reasons for the lack of a relationship between social anxiety and substance use in the younger group. The first one is that substance use in this group was very low which restricted the variance of the dependent variable and therefore the size of the correlations. Secondly, the number of participants in the younger age group was relatively small which made it less likely that tests were significant. However, although not significant, the results of the younger group showed an emerging pattern, especially concerning the role of susceptibility to peer influence, that is rather similar to that of the older age group.

Previous studies have shown that in adolescence susceptibility to peer pressure declines with age [30,31]. However, the present study's results do not corroborate these findings. In the present study, the older adolescents were not less susceptible to peer pressure than the younger ones. This finding is difficult to explain, more so because it was found in both samples of the study. One could note that the mean scores of Sample 2 do show lower susceptibility in the older group, although the difference is not statistically significant. Possibly, if the age difference between younger and older groups had been larger, the decline in susceptibility to peer pressure between the groups would also have been larger with a significant age effect as a result.

There are some limitations to this study that have to be taken into account. (1) The design of the study with social anxiety, susceptibility to peer influence, and initial substance use all measured at the same time point does not test for a causal order. Although at the young age of the participants it is not likely that substance use caused social anxiety or susceptibility to peer influence or that susceptibility to peer pressure caused social anxiety, we strictly cannot exclude it. (2) The analyses did not distinguish between specific substances used and how much participants used of these substances. We therefore do not know the relative importance of drinking, smoking, or using cannabis in the study's results. However, from previous research, we do know that the developmental relation between peer relationships and substance use may differ between substances [27]. (3) Because the study used a nonreferred community sample, the conclusions may not be valid for clinically socially anxious adolescents. (4) We did not test gender effects in the study. Previous research suggests that gender does play a role in the relationship between anxiety and substance use and in adolescents' susceptibility to peer pressure. (5) Possible dependence in the data as a result of using participants from the same schools and classes was not taken into account.

\section{Conclusion}

The link between social anxiety and substance use in adolescence may be partly explained by susceptibility to peer pressure. New longitudinal studies will be needed to sketch the causal paths from adolescents' social anxiety to adults' substance problems or ultimately substance abuse disorder. The role of susceptibility to peer pressure and gender should be examined in this developmental process. Knowledge about the importance of susceptibility to peer pressure may help to prevent initial substance use in socially anxious youth and consequent substance use dependence and problems in socially anxious adults.

\section{Competing Interests}

The authors declare that there is no conflict of interests regarding the publication of this paper.

\section{References}

[1] K. R. Merikangas, S. Avenevoli, S. Acharyya, H. Zhang, and J. Angst, "The spectrum of social phobia in the Zurich cohort study of young adults," Biological Psychiatry, vol. 51, no. 1, pp. 81-91, 2002.

[2] R. M. Crum and L. A. Pratt, "Risk of heavy drinking and alcohol use disorders in social phobia: a prospective analysis," American Journal of Psychiatry, vol. 158, no. 10, pp. 1693-1700, 2014.

[3] A. M. Eggleston, K. Woolaway-Bickel, and N. B. Schmidt, "Social anxiety and alcohol use: evaluation of the moderating 
and mediating effects of alcohol expectancies," Journal of Anxiety Disorders, vol. 18, no. 1, pp. 33-49, 2004.

[4] L. S. Ham and D. A. Hope, "Incorporating social anxiety into a model of college student problematic drinking," Addictive Behaviors, vol. 30, no. 1, pp. 127-150, 2005.

[5] APA, Diagnostic and Statistical Manual of Mental Disorders, American Psychiatric Association, Arlington, Va, USA, 2013.

[6] R. M. Rapee and S. H. Spence, "The etiology of social phobia: empirical evidence and an initial model," Clinical Psychology Review, vol. 24, no. 7, pp. 737-767, 2004.

[7] P. M. Westenberg, M. J. Drewes, A. W. Goedhart, B. M. Siebelink, and P. D. A. Treffers, "A developmental analysis of self-reported fears in late childhood through mid-adolescence: social-evaluative fears on the rise?" Journal of Child Psychology and Psychiatry, vol. 45, no. 3, pp. 481-495, 2004.

[8] M. Burstein et al., "Social phobia and subtypes in the national comorbidity survey-adolescent supplement: prevalence, correlates, and comorbidity, Journal of the American Academy of Child \& Adolescent Psychiatry, vol. 50, no. 9, pp. 870-880, 2011.

[9] C. A. Essau, J. Conradt, and F. Petermann, "Frequency and comorbidity of social phobia and social fears in adolescents," Behaviour Research and Therapy, vol. 37, no. 9, pp. 831-843, 1999.

[10] H.-U. Wittchen, M. B. Stein, and R. C. Kessler, "Social fears and social phobia in a community sample of adolescents and young adults: prevalence, risk factors and co-morbidity," Psychological Medicine, vol. 29, no. 2, pp. 309-323, 1999.

[11] P. C. Kendall, S. Safford, E. Flannery-Schroeder, and A. Webb, "Child anxiety treatment: outcomes in adolescence and impact on substance use and depression at 7.4-year follow-up," Journal of Consulting and Clinical Psychology, vol. 72, no. 2, pp. 276-287, 2004.

[12] M. Vogel, C. E. Rees, T. McCuddy, and D. C. Carson, "The highs that bind: school context, social status and marijuana use," Journal of Youth and Adolescence, vol. 44, no. 5, pp. 1153-1164, 2015.

[13] O. E. Atherton, R. D. Conger, E. Ferrer, and R. W. Robins, "Risk and protective factors for early substance use initiation: a longitudinal study of Mexican-origin youth," Journal of Research on Adolescence, 2015.

[14] B. F. Grant and D. A. Dawson, "Age at onset of alcohol use and its association with DSM-IV alcohol abuse and dependence: results from the National Longitudinal Alcohol Epidemiologic Survey," Journal of Substance Abuse, vol. 9, no. 1, pp. 103-110, 1997.

[15] G. C. Patton, J. B. Carlin, C. Coffey, R. Wolfe, M. Hibbert, and G. Bowes, "Depression, anxiety, and smoking initiation: a prospective study over 3 years," American Journal of Public Health, vol. 88, no. 10, pp. 1518-1522, 1998.

[16] H. Sonntag, H. U. Wittchen, M. Höfler, R. C. Kessler, and M. B. Stein, "Are social fears and DSM-IV social anxiety disorder associated with smoking and nicotine dependence in adolescents and young adults?" European Psychiatry, vol. 15, no. 1, pp. 67-74, 2000.

[17] M. J. Prinstein, J. Boergers, and A. Spirito, “Adolescents' and their friends' health-risk behavior: factors that alter or add to peer influence," Journal of Pediatric Psychology, vol. 26, no. 5, pp. 287-298, 2001.

[18] R. C. Kessler, M. B. Stein, and P. Berglund, "Social phobia subtypes in the National Comorbidity Survey," The American Journal of Psychiatry, vol. 155, no. 5, pp. 613-619, 1998.
[19] N. R. Marmorstein, H. R. White, R. Loeber, and M. StouthamerLoeber, "Anxiety as a predictor of age at first use of substances and progression to substance use problems among boys," Journal of Abnormal Child Psychology, vol. 38, no. 2, pp. 211-224, 2010.

[20] J. D. Buckner, N. B. Schmidt, A. R. Lang, J. W. Small, R. C. Schlauch, and P. M. Lewinsohn, "Specificity of social anxiety disorder as a risk factor for alcohol and cannabis dependence," Journal of Psychiatric Research, vol. 42, no. 3, pp. 230-239, 2008.

[21] P. J. Fite, C. R. Colder, and R. M. O'Connor, "Childhood behavior problems and peer selection and socialization: risk for adolescent alcohol use," Addictive Behaviors, vol. 31, no. 8, pp. 1454-1459, 2006.

[22] T. D. Armstrong and E. J. Costello, "Community studies on adolescent substance use, abuse, or dependence and psychiatric comorbidity," Journal of Consulting and Clinical Psychology, vol. 70, no. 6, pp. 1224-1239, 2002.

[23] M. A. Bruch, K. M. Rivet, R. G. Heimberg, and M. A. Levin, "Shyness, alcohol expectancies, and drinking behavior: replication and extension of a suppressor effect," Personality and Individual Differences, vol. 22, no. 2, pp. 193-200, 1997.

[24] R. M. Arkin, E. A. Lake, and A. H. Baumgardner, "Shyness and self-presentation," in Shyness, pp. 189-203, Springer, Berlin, Germany, 1986.

[25] E. P. Morris, S. H. Stewart, and L. S. Ham, "The relationship between social anxiety disorder and alcohol use disorders: a critical review," Clinical Psychology Review, vol. 25, no. 6, pp. 734-760, 2005.

[26] J. D. Buckner, M. A. Mallott, N. B. Schmidt, and J. Taylor, "Peer influence and gender differences in problematic cannabis use among individuals with social anxiety," Journal of Anxiety Disorders, vol. 20, no. 8, pp. 1087-1102, 2006.

[27] S. T. Ennett, K. E. Bauman, A. Hussong et al., "The peer context of adolescent substance use: findings from social network analysis," Journal of Research on Adolescence, vol. 16, no. 2, pp. 159-186, 2006.

[28] B. B. Brown, S. A. Eicher, and S. Petrie, "The importance of peer group ('crowd') affiliation in adolescence," Journal of Adolescence, vol. 9, no. 1, pp. 73-96, 1986.

[29] W. A. Collins and L. Steinberg, "Adolescent development in interpersonal context," in Handbook of Child Psychology: Vol. 3. Social, Emotional, and Personality Development, W. Damon and R. Lerner, Eds., vol. 3, pp. 1003-1067, John Wiley \& Sons, New York, NY, USA, 2006.

[30] S. R. Sumter, C. L. Bokhorst, L. Steinberg, and P. M. Westenberg, "The developmental pattern of resistance to peer influence in adolescence: will the teenager ever be able to resist?" Journal of Adolescence, vol. 32, no. 4, pp. 1009-1021, 2009.

[31] L. Steinberg and K. C. Monahan, "Age differences in resistance to peer influence," Developmental Psychology, vol. 43, no. 6, pp. 1531-1543, 2007.

[32] W. W. Hartup, "Peer interaction: what causes what?" Journal of Abnormal Child Psychology, vol. 33, no. 3, pp. 387-394, 2005.

[33] A. M. Griffin, H. H. Cleveland, G. L. Schlomer, D. J. Vandenbergh, and M. E. Feinberg, "Differential susceptibility: the genetic moderation of peer pressure on alcohol use," Journal of Youth and Adolescence, vol. 44, no. 10, pp. 1841-1853, 2015.

[34] J. P. Allen, J. Chango, D. Szwedo, M. Schad, and E. Marston, "Predictors of susceptibility to peer influence regarding substance use in adolescence," Child Development, vol. 83, no. 1, pp. 337-350, 2012. 
[35] J. T. Lashbrook, "Fitting in: exploring the emotional dimension of adolescent peer pressure," Adolescence, vol. 35, no. 140, pp. 747-758, 2000.

[36] B. B. Brown, D. R. Clasen, and S. A. Eicher, "Perceptions of peer pressure, peer conformity dispositions, and self-reported behavior among adolescents," Developmental Psychology, vol. 22, no. 4, pp. 521-530, 1986.

[37] D. P. MacKinnon, J. L. Krull, and C. M. Lockwood, "Equivalence of the mediation, confounding and suppression effect," Prevention Science, vol. 1, no. 4, pp. 173-181, 2000.

[38] D. D. Rucker, K. J. Preacher, Z. L. Tormala, and R. E. Petty, "Mediation analysis in social psychology: current practices and new recommendations," Social and Personality Psychology Compass, vol. 5, no. 6, pp. 359-371, 2011.

[39] Trimbos Instituut, Nationale Drug Monitor 2013-2014, Trimbos Instituut, TB Utrecht, The Netherlands, 2014.

[40] A. M. La Greca and N. Lopez, "Social anxiety among adolescents: linkages with peer relations and friendships," Journal of Abnormal Child Psychology, vol. 26, no. 2, pp. 83-94, 1998.

[41] P. M. Westenberg, C. L. Bokhorst, A. C. Miers et al., "A prepared speech in front of a pre-recorded audience: subjective, physiological, and neuroendocrine responses to the Leiden public speaking task," Biological Psychology, vol. 82, no. 2, pp. 116-124, 2009.

[42] A. C. Miers, A. W. Blöte, M. De Rooij, C. L. Bokhorst, and P. M. Westenberg, "Trajectories of social anxiety during adolescence and relations with cognition, social competence, and temperament," Journal of Abnormal Child Psychology, vol. 41, no. 1, pp. 97-110, 2013.

[43] A. C. Miers, A. W. Blöte, S. M. Bögels, and P. M. Westenberg, "Interpretation bias and social anxiety in adolescents," Journal of Anxiety Disorders, vol. 22, no. 8, pp. 1462-1471, 2008.

[44] S. Harter, Manual for the Self-Perception Profile For Adolescents, Department of Psychology, University of Denver, Denver, Colo, USA, 1988.

[45] A. F. Hayes, "An index and test of linear moderated mediation," Multivariate Behavioral Research, vol. 50, no. 1, pp. 1-22, 2015.

[46] SAMHSA, Results from the 2013 National Survey on Drug Use and Health: Summary of National Findings, SAMHSA, Rockville, Md, USA, 2014.

[47] S. Lev-Ran, Y. Le Strat, S. Imtiaz, J. Rehm, and B. Le Foll, "Gender differences in prevalence of substance use disorders among individuals with lifetime exposure to substances: results from a large representative sample," The American Journal on Addictions, vol. 22, no. 1, pp. 7-13, 2013.

[48] K. L. Tomlinson, K. M. Cummins, and S. A. Brown, "Social anxiety and onset of drinking in early adolescence," Journal of Child \& Adolescent Substance Abuse, vol. 22, no. 2, pp. 163-177, 2013.

[49] L. S. Ham, M. Bonin, and D. A. Hope, "The role of drinking motives in social anxiety and alcohol use," Journal of Anxiety Disorders, vol. 21, no. 8, pp. 991-1003, 2007.

[50] M. H. Carrigan and C. L. Randall, "Self-medication in social phobia: a review of the alcohol literature," Addictive Behaviors, vol. 28, no. 2, pp. 269-284, 2003.

[51] J. J. Conger, "Alcoholism: theory, problem and challenge. II. Reinforcement theory and the dynamics of alcoholism," Quarterly Journal of Studies on Alcohol, vol. 17, no. 2, pp. 296-305, 1956.

[52] K. J. Sher and R. W. Levenson, "Risk for alcoholism and individual differences in the stress-response-dampening effect of alcohol," Journal of Abnormal Psychology, vol. 91, no. 5, pp. 350-367, 1982.

[53] H. Blumenthal, E. W. Leen-Feldner, J. L. Frala, C. L. Badour, and L. S. Ham, "Social anxiety and motives for alcohol use among adolescents," Psychology of Addictive Behaviors, vol. 24, no. 3, pp. 529-534, 2010. 


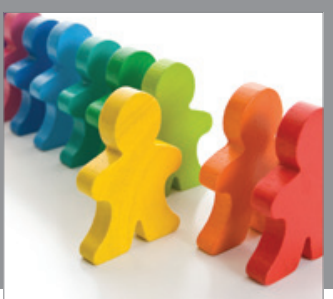

Autism

Research and Treatment
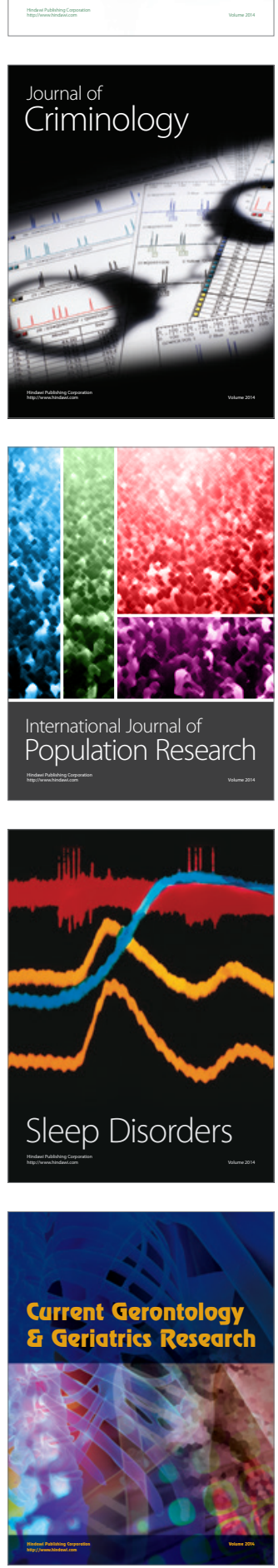

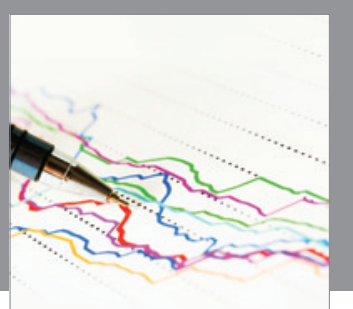

Economics

Research International
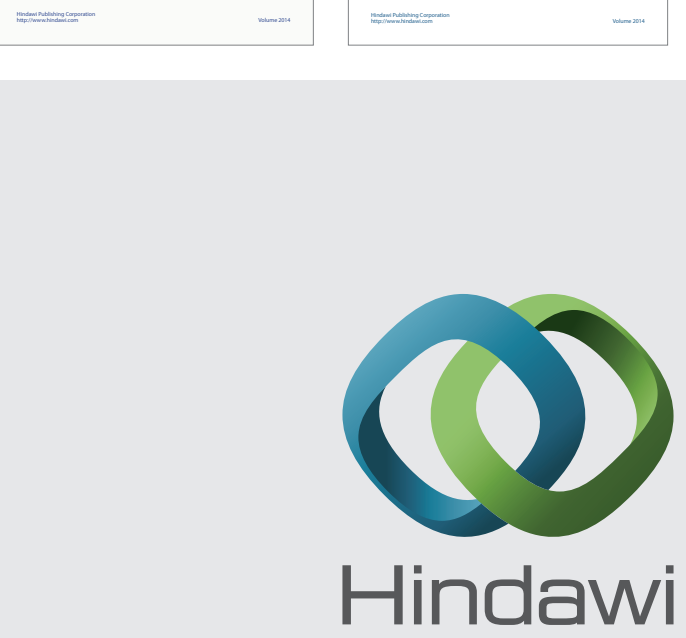

Submit your manuscripts at

http://www.hindawi.com
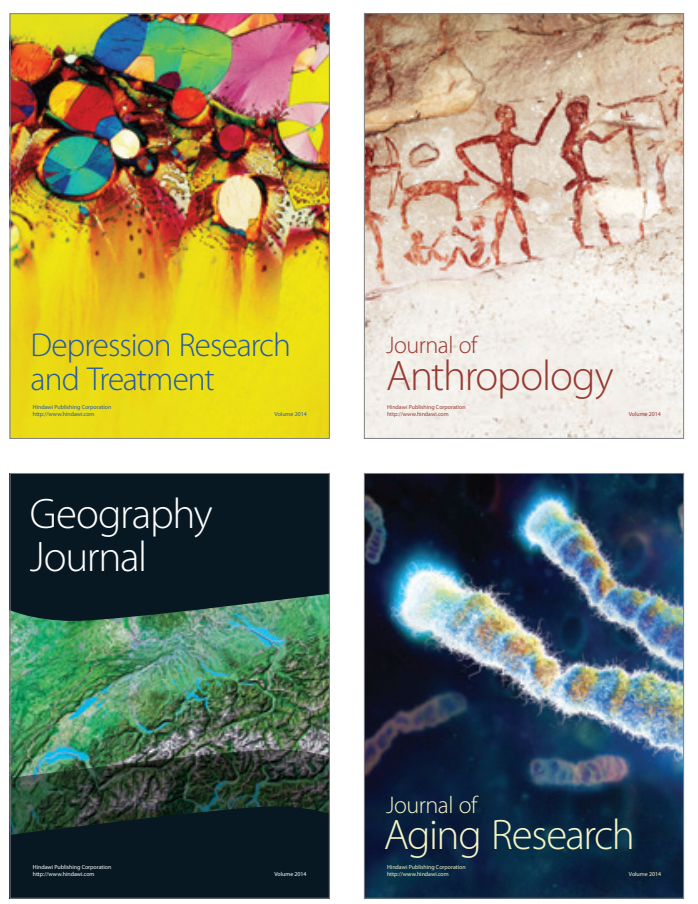
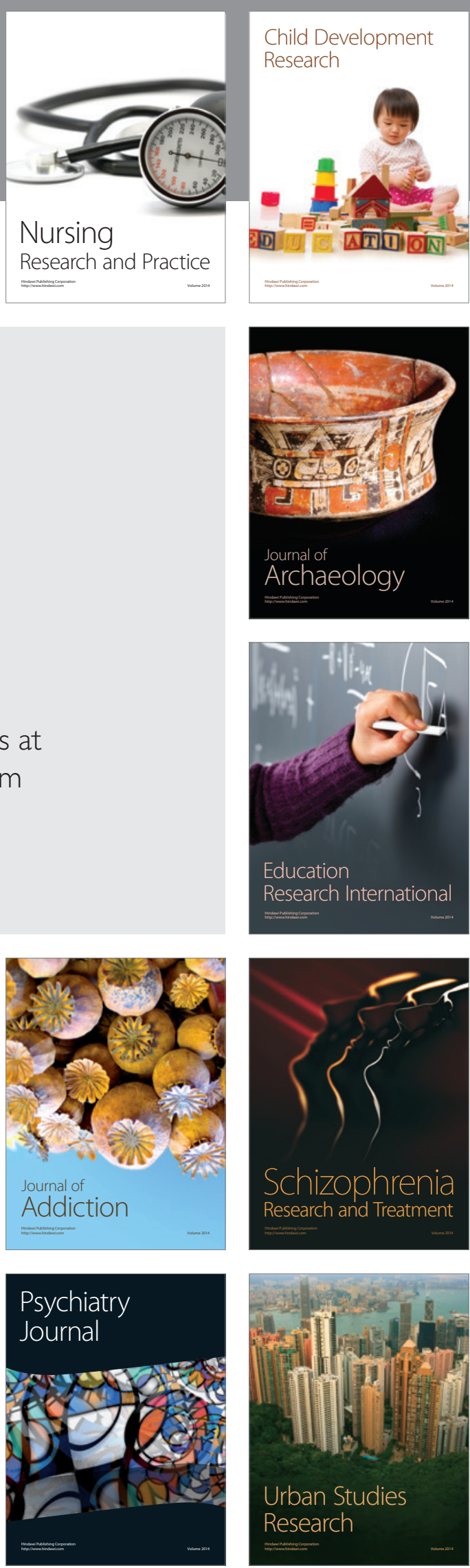